\title{
A construção de políticas públicas para a sustentabilidade urbana
}

\section{The construction of public policies for urban sustainability}

\section{La construcción de políticas públicas para la sostenibilidad urbana}

\author{
Alex Dias da Silva ${ }^{1}$ \\ Instituto Federal da Paraíba (IFPB), Brasil
}

\begin{abstract}
Resumo
Nas últimas décadas, o poder público tem cada vez mais se esforçado a incorporar as políticas públicas na agenda do desenvolvimento sustentável, isso em decorrência do processo de crescimento desordenado das cidades. Nesse contexto, o objetivo desse trabalho é investigar sobre a constituição de políticas governamentais que fomentam a Agricultura Urbana, como instrumento de sustentabilidade urbana, na cidade de João Pessoa-PB. Por ser um fenômeno recente, a presença de marco legislativo específico para a promoção da Agricultura Urbana deve ser analisada. A metodologia empregada foi pesquisa qualitativa, de natureza descritiva e exploratória. O trabalho revelou a existência de políticas públicas que o governo municipal vem fomentando, desde o ano de 1993, o desenvolvimento de ações voltadas para a gestão e o aperfeiçoamento das práticas de Agricultura Urbana.
\end{abstract}

Palavras chave: Segurança Alimentar e Nutricional. Sustentabilidade Urbana. Agricultura Urbana. Políticas Públicas.

\begin{abstract}
In the last decades, public power has been increasingly striving to incorporate public policies into the sustainable development agenda, as a result of the disorderly growth process of cities. In this context, the objective of this work is to investigate the constitution of government policies that promote Urban Agriculture, as an instrument of urban sustainability, in the city of João Pessoa-PB.

1 Professor, Instituto Federal da Paraíba (IFPB), Brasil. Engenheiro Agrônomo e Mestre em Engenharia Civil e Ambiental pela Universidade Federal da Paraíba (UFPB), Brasil. Graduado em Direito pela Instituto Paraibano de Ensino Renovado (INPER), Brasil. E-mail: alexdiasds@hotmail.com. https://orcid.org/00000001-8895-2134
\end{abstract}


Because it is a recent phenomenon, the presence of a specific legislative framework for the promotion of Urban Agriculture must be analyzed. The methodology used was qualitative research, of a descriptive and exploratory nature. The work revealed the existence of public policies that the municipal government has been promoting, since 1993, the development of actions aimed at the management and improvement of Urban Agriculture practices.

Keywords: Food and nutrition security. Urban Sustainability. Urban Agriculture. Public Policy.

\begin{abstract}
Resumen
En las últimas décadas, el poder público se ha esforzado cada vez más por incorporar políticas públicas en la agenda del desarrollo sostenible, como resultado del proceso de crecimiento desordenado de las ciudades. En este contexto, el objetivo de este documento es investigar la constitución de políticas gubernamentales que promuevan la agricultura urbana, como instrumento de sostenibilidad urbana, en la ciudad de João Pessoa-PB. Como fenómeno reciente, debe analizarse la presencia de un marco legislativo específico para la promoción de la agricultura urbana. La metodología utilizada fue la investigación cualitativa, descriptiva y de naturaleza exploratoria. El trabajo reveló la existencia de políticas públicas que el gobierno municipal ha estado promoviendo, desde 1993, el desarrollo de acciones dirigidas a la gestión y mejora de las prácticas de agricultura urbana.
\end{abstract}

Palabras clave: Seguridad Alimentaria y Nutricional. Sostenibilidad urbana. Agricultura urbana Políticas públicas.

\title{
Introdução
}

Nas últimas décadas, principalmente, a partir de 1980, a crescente urbanização se alastrou por todo cenário nacional, seguindo a tendência mundial. Isso vem provocando a redução da população rural. No relatório Perspectivas da Urbanização Mundial, a ONU aponta que 54\% da população vivem em áreas urbanas. Por evidente, isso implica no risco às atuais e futuras condições de sustentabilidade ambiental e de saúde de populações residentes em grandes aglomerações.

O desenvolvimento da agricultura na cidade tende a transpassar as barreiras convencionais da economia, meio ambiente, cultural, social e urbanismo, é a chamada resiliência urbana. Os altos níveis de crescimento das cidades se relacionam diretamente aos índices de pobreza e insegurança alimentar dessas populações.

Por esse motivo, o planejamento urbano deve ser adequadamente elaborado, planejado e integrado com a formação de políticas públicas com o mister de fomentar a AU, pois esta é uma atividade específica e sistêmica, podendo estar inserida tanto em espaços públicos, quando privados, além de ser praticada tanto em coletividade quanto de forma individual. 
Nesse contexto, se insere o debate sobre a constituição de políticas governamentais que fomentam a AU, uma forma de garantir a segurança alimentar e nutricional da população, em especial das famílias vulneráveis, favorecendo uma dieta alimentar e nutricional rica e digna, ao mesmo tempo em que possibilita o aumento do seu poder aquisitivo e a promoção da agricultura sustentável.

Essa ideia também faz parte da política governamental inserida no plano de ação da "Agenda 2030", documento adotado na Cúpula das Nações Unidas sobre o Desenvolvimento Sustentável, no ano de 2015, o qual traça os 17 Objetivos do Desenvolvimento Sustentável e as metas a serem alcançadas.

O estudo em questão se utilizou de uma abordagem do tipo qualitativa, de natureza descritiva e exploratória, envolvendo processos de revisão bibliográfica e estudo literário, onde exige uma síntese de informações fundamentadas em diversos tópicos que sejam capazes de dar ao caso uma ampla compreensão.

O universo da pesquisa compreende a cidade de João Pessoa/PB, capital do Estado da Paraíba (Figura 1). Enquanto que o recorte do objeto contempla as políticas públicas que alcancem a produção de alimentos em ambiente urbano (Agricultura Urbana).

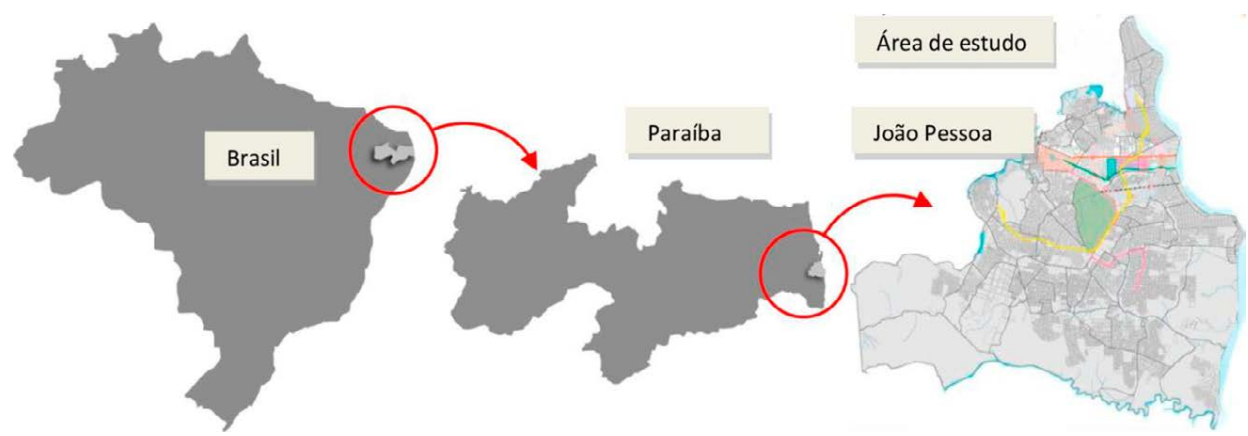

Figura 1. Mapa de localização da cidade de João Pessoa, no Estado brasileiro da Paraíba.

Fonte: Silva (2018), adaptado de Tabosa et al. (2018).

\section{Desenvolvimento sustentável urbano e agricultura urbana}

O conceito de desenvolvimento sustentável é amplamente discutido, contudo, tem-se como primazia que este se baseia em três pilares (Figura 2), 
sendo eles: o social, o ecológico e o econômico. Esse conceito vem da premissa de que, para gerar um desenvolvimento econômico, de acordo com as necessidades da geração atual, deve-se preocupar com a preservação do meio ambiente, sem comprometer a capacidade para as gerações futuras.

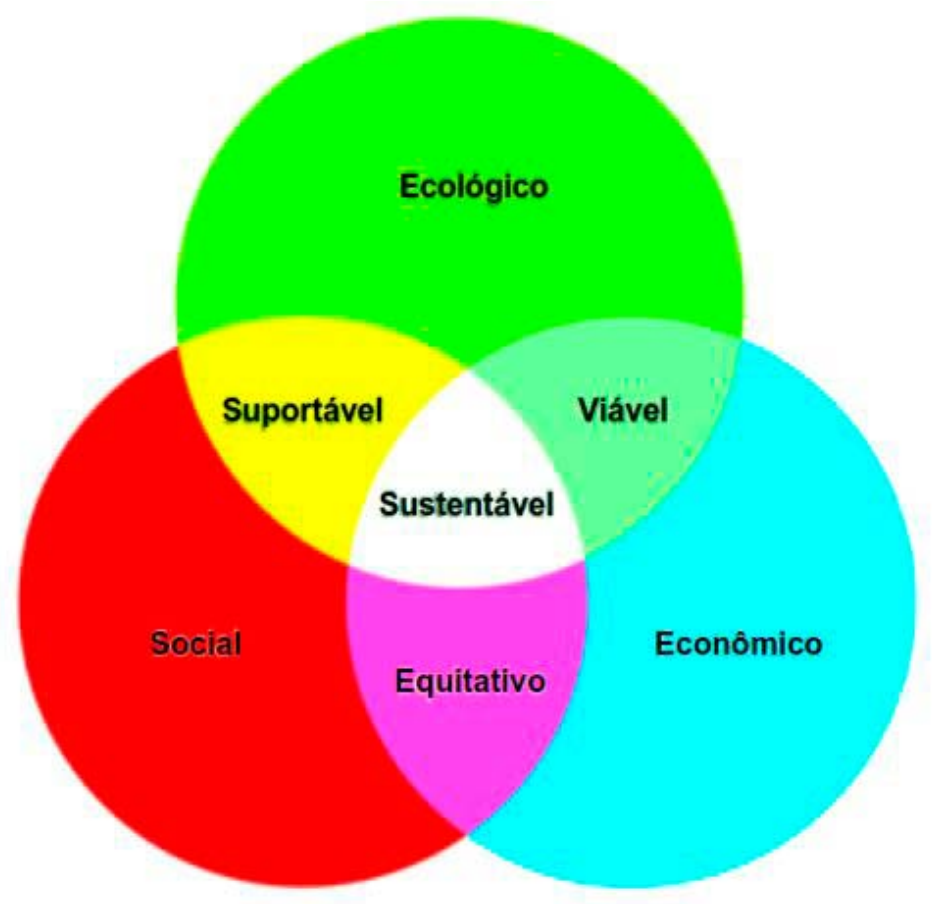

Figura 2. Pilares do Desenvolvimento Sustentável.

Fonte: Autoria própria (2018).

Entre as noções de sustentabilidade, pode-se destacar a eficiência, que pretende combater o desperdício de recursos no meio do processo de desenvolvimento, estendendo a noção de racionalidade econômica a todos os recursos do planeta, desde recursos mais abundantes como a água até recursos mais escassos.

Isso significa dar oportunidade para que as gerações, atual e futura, alcancem um nível razoável de desenvolvimento social e econômico e de realização humana e cultural, fazendo, ao mesmo tempo, um uso razoável e duradouro dos recursos da terra, preservando o meio ambiente como um todo. 
Contudo, é lícito afirmar que a sustentabilidade pode ser caracterizada como um nexo temporal entre os momentos e recursos situados no tempo: passado e presente, presente e futuro

A noção de desenvolvimento sustentável teve abrangente visibilidade nos últimos anos, procurando aproximar a temática do crescimento econômico com a do meio ambiente.

Para Veiga (2010, p. 208), as diversas versões do conceito de “desenvolvimento sustentável" são consideradas uma utopia para o século XXI, estando distante de se delimitar, considerando assim este termo um enigma a ser dissecado.

Ainda segundo o autor (Veiga, 2010, p. 188), quando relacionar o desenvolvimento econômico com o meio ambiente, se torna necessário ter conhecimentos prévios e basilares, no que diz respeito ao comportamento humano, evolução da natureza e no desenvolvimento territorial.

A noção de desenvolvimento sustentável, de tanta importância nos últimos anos, procura vincular estreitamente a temática do crescimento econômico com a do meio ambiente. Para compreender tal vinculação, são necessários alguns conhecimentos fundamentais que permitem relacionar pelo menos três âmbitos: a) o dos comportamentos humanos, econômicos e sociais que são objeto da teoria econômica e das demais ciências sociais; b) o da evolução da natureza, que é objeto das ciências biológicas, físicas e químicas; c) o da configuração social do território, que é objeto da geografia humana, das ciências regionais e da organização do espaço. (Veiga, 2010, p. 188).

Nesse mister, o desenvolvimento voltado apenas para o crescimento econômico sem melhoria de qualidade de vida das pessoas e das sociedades não pode ser considerado desenvolvimento, mas sim uma fragilidade no sistema. É possível alcançar maior desenvolvimento sem destruir os recursos naturais conciliando crescimento econômico com a conservação ambiental.

A interligação dessas vertentes cria um tripé que apoia o desenvolvimento sustentável, adotando medidas que envolvam o poder público, a iniciativa privada e a sociedade, criando assim uma harmonização de objetivos econômicos, ambientais e sociais (Figura 3). 


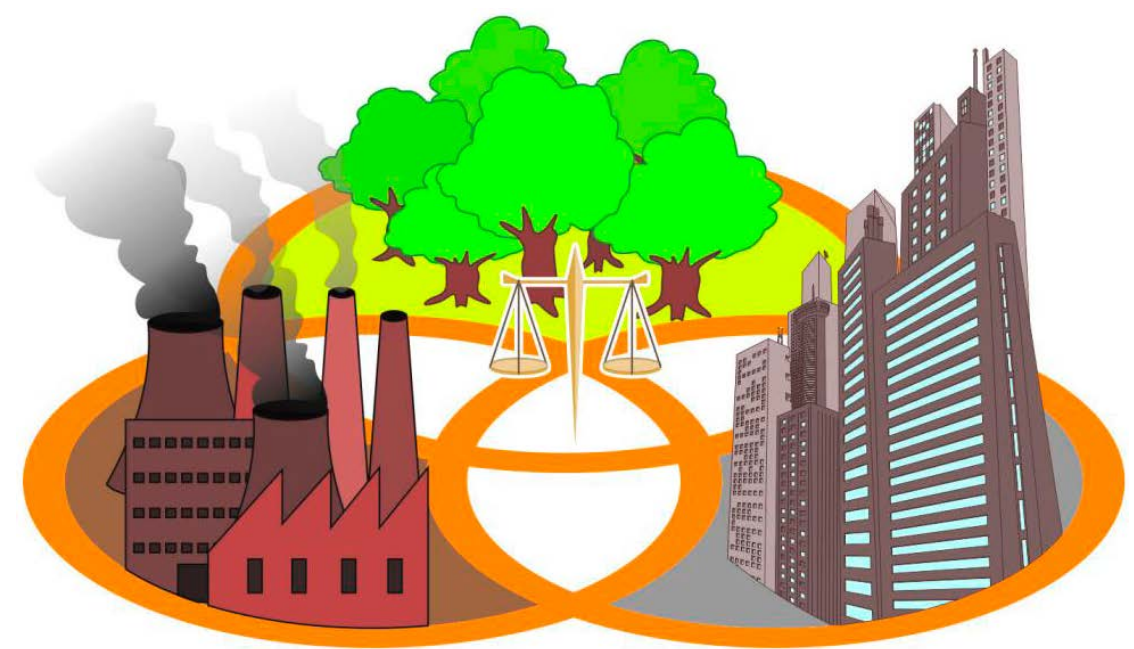

Figura 3. Harmonização entre protagonistas do desenvolvimento sustentável.

Fonte: Ruppenthal (2014, p. 33)

Com relação à iniciativa privada, Barbieri \& Cajazeira (2009, p. 70) destaca a importância da organização de uma empresa sustentável, a qual procura:

[...] incorporar os conceitos e objetivos relacionados com o desenvolvimento sustentável em suas políticas e práticas de modo consistente [...]. Para a empresa, a incorporação desses objetivos significa adotar estratégias de negócios e atividades que atendam as necessidades das empresas e dos seus stakeholders atuais, enquanto protegem, sustentam e aumentam os recursos humanos e naturais que serão necessários no futuro. (Barbieri \& Cajazeira, 2009, p. 70).

A proposta do desenvolvimento urbano sustentável é um argumento que foi resgatado por uma parte dos autores contemporâneos verificados na literatura, sendo acrescido também ao campo das Organizações Não Governamentais, que veem na ideia do planejamento sustentável um novo modo de ver a organização urbana, modo que está destinando a tomar o lugar da ideia de uma organização meramente espacial, construindo um princípio organizador que lide com as várias facetas da sustentabilidade.

Para ser considerada uma cidade sustentável significa é preciso que esta promova a boa utilização dos recursos ambientais em prol da 
ampliação da qualidade de vida geral da população, onde os recursos, a longo e a curto prazo, sejam de fontes renováveis com a finalidade de promover o bom uso do ambiente.

Nessa situação, constata-se a indispensabilidade da sustentabilidade urbana, de modo que a forma de como é tratada atualmente, com base no lucro e com regalia para poucos, seja reestruturada.

Em relação ao conceito de $\mathrm{AU}$, cabe mencionar o entendimento de Stewart et al. (2013, p. 2), "a agricultura urbana não é facilmente definida, uma vez que existe uma grande variedade de sistemas de agricultura urbana a nível internacional, com características variadas dependendo das condições socioeconômicas, geográficas e políticas locais".

De forma universal, a AU, em síntese, pode ser considerada como produção de alimentos dentro da cidade.

A prática de agricultura em meio urbano difere da agricultura rural pelo ambiente em que se insere, podendo abranger uma grande variedade de tipologias (Pinto, 2007, p. 54). Cabe destacar a tipologia chamada de hortas urbanas, principal forma de praticar a agricultura no espaço urbano e constituem uma maneira de utilizar espaços nas cidades, produzindo hortaliças, árvores frutíferas e plantas ornamentais.

Uma das características mais relevantes da AU é sua capacidade de interagir com outros campos temáticos, como o econômico, social e ao meio ambiente urbano, fazendo com que a AU se considere uma dimensão do desenvolvimento urbano sustentável. Além desses, a AU está intimamente ligada aos eixos da saúde, geração de renda, segurança alimentar e nutricional, e na gestão das políticas públicas, tema da pesquisa deste trabalho.

A presença da AU na cidade atinge a economia local, o ambiente natural, as relações sociais e o comportamento econômico das famílias (Mougeot, 2000, p. 15).

Segundo Mougeot (2000, p. 7) para se caracterizar uma iniciativa de AU, é necessário se basear nos seguintes determinantes (Figura 4): tipo de atividade econômica, localização ${ }^{2}$, tipos de áreas onde ela é praticada; sua escala e sistema de produção; as categorias e subcategorias de produtos (alimentícios e não alimentícios); e a destinação dos produtos, inclusive sua comercialização.

2 Quando a localização onde a Agricultura Urbana é desenvolvida, esta pode ser dividida em duas: sendo chamada de agricultura intra-urabana, quando praticada no interior (ou centro urbano) e agricutlura periurbana quando localizada na periferia de uma localidade ou cidade. 


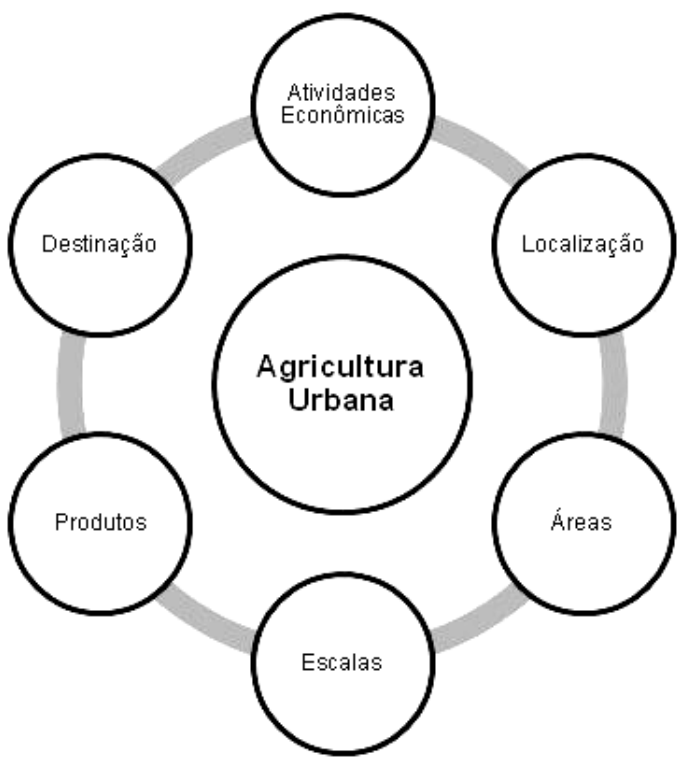

Figura 4. Determinantes da Agricultura Urbana

Fonte: Mougeot (2000).

Cabe destacar que, a AU tem sustentação no uso de espaços públicos ou privados, coletivos ou individuais, para a produção de alimentos para consumo próprio ou para venda em mercados locais e até mesmo regionais.

A falta de apoio e incentivo financeiro por parte do poder público é um entrave para o desenvolvimento da $\mathrm{AU}$, esse fato pode estar relacionado a falta de conhecimento, por parte do poder público, dos benefícios que a $\mathrm{AU}$ pode levar para a sociedade.

Existe uma grande variedade de sistemas de $\mathrm{AU}$ a nível nacional, com características variadas de implantação, dependendo das condições socioeconômicas, geográficas, das políticas locais e da legislação de cada cidade.

\section{O Direito e o Meio Ambiente}

Em primeiro lugar, destaca-se que a área do conhecimento jurídico que tem como premissa estudar as interações do homem com a natureza, bem como os mecanismos legais para proteção do meio ambiente é o Direito Ambiental. Importante realçar que, a tutela ambiental é realizada de forma holística - o meio ambiente é regulado como um todo e não de forma fracionada.

A Lei $n^{\circ} 6.938$, de 31 de agosto de 1981, recepcionada pela CRFB de 1988, dispõe da Política Nacional do Meio Ambiente. Esta lei aponta uma séria de medidas de ordem administrativa e civil, que à época de sua edição foram tidas como necessárias à tutela do meio ambiente.

Em seu artigo $2^{\circ}$, este dispositivo oferece um conceito objetivo de desenvolvimento sustentável e estabelece um marco definitivo e considerável na conscientização dos problemas ambientais: 
"A Política Nacional do Meio Ambiente tem por objetivo a preservação, melhoria e recuperação da qualidade ambiental propícia à vida, visando assegurar, no País, condições ao desenvolvimento socioeconômico, aos interesses da segurança nacional e à proteção da dignidade da vida humana [...]”.

Além desse dispositivo legal, outros três instrumentos jurídicos formam a base legislativa ${ }^{3}$ da proteção ambiental brasileira (Figura 5), que se preocupam, de forma isolada com algum aspecto do meio ambiente.

Convém frisar que, a Constituição Federal de 1988 incluiu o tema em seu contexto, na categoria dos direitos fundamentais do cidadão. Diz o artigo 225 da Constituição Federal que:

Todos têm direito ao meio ambiente ecologicamente equilibrado, bem de uso comum do povo e essencial à sadia qualidade de vida, impondo-se ao poder público e à coletividade o dever de defendê-lo e preservá-lo para as presentes e futuras gerações [...].

A CRFB de 1988, além de possuir um capítulo próprio para as questões ambientais (Capítulo VI - Do Meio Ambiente), traz, no decorrer da Carta, diversos outros artigos, das obrigações da sociedade e do Estado brasileiro para com o meio ambiente.

$\mathrm{O}$ direito ambiental está essencialmente ligado ao desenvolvimento sustentável. Assim como

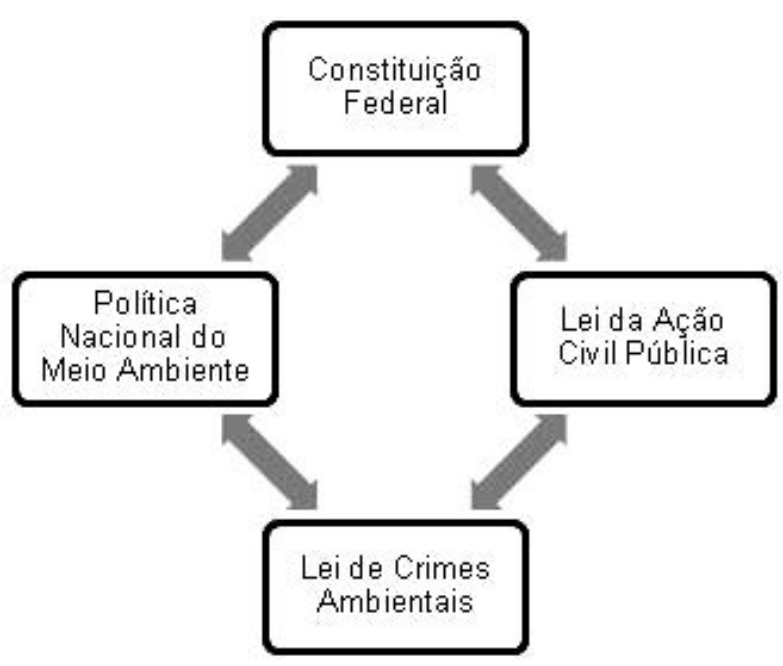

Figura 5. Pilares legislativos da proteção ambiental brasileira. Fonte: Elaboração própria (2018).

3 São considerados os pilares legislativos da proteção ambiental, a Lei n 7.347 , de 24 de julho de 1985 , que disciplina a ação civil pública como instrumento processual específico para a defesa do meio ambiente; A Carta Magna de 1988 e a Lei de Crimes Ambientais, regulado pela Lei nº 9.605, de 12 de fevereiro de 1988. 
os demais ramos do direito, este é constituído de princípios norteadores ${ }^{4}$, cabendo destacar dois, o Princípio do Desenvolvimento Sustentável e o Princípio da Preservação.

Primeiro, o Princípio do Desenvolvimento Sustentável estabelece como alicerce a necessidade de estabilidade (relação harmônica) entre o desenvolvimento econômico e a proteção do meio ambiente. Nesse óbice, caso uma atividade ofereça risco de dano ao ambiente é licito que o poder público intervenha de forma a cessar a atividade. Portanto, tal princípio estabelece um dever jurídico de evitar o dano ambiental e dá operabilidade aos demais princípios, tem por berço o caput do artigo 225 da CRFB.

O Princípio da Prevenção da Natureza é utilizado quando já se conhecem os efeitos nocivos de determinada atividade, buscando que sejam tomadas as medidas necessárias para se evitar ou diminuir os danos causados ao meio ambiente. Neste contexto, tem previsão constitucional inserta no $\S 3^{\circ}$ do artigo 225 da CRFB:

[...] as condutas e atividades consideradas lesivas ao meio ambiente sujeitarão os infratores, pessoas físicas ou jurídicas, a sanções penais e administrativas, independentemente da obrigação de reparar os danos causados.

Por fim, o Princípio da Prevenção, juntamente com o Princípio da Precaução, funciona como uma ação de antecipação, frente a uma previsão de risco ou perigo de dano ao meio ambiente, responsabilizando a prática de condutas contrárias a essa preservação.

\section{Competência em matéria de Direito Ambiental}

O Brasil por se tratar de uma república federativa, caracteriza-se pela união indissolúvel das entidades federativas que o constituem, tais qual a união, os Estados, o Distrito Federal e os municípios (vide artigo 18 da CRFB).

A harmonização e compatibilização dessas esferas internas de poder

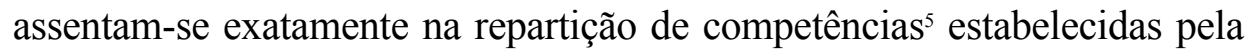

4 Esses princípios formam as bases do sistema jurídico ambiental, de forma que todos tem foco na utilização dos bens ambientais de forma harmoniosa, com a preservação dos recursos naturais.

5 Segundo Bastos (2001, p. 107), competência são os poderes que a lei confere para que cada órgão público possa desempenhar suas atribuições específicas. 
Carta Magna, de forma que o exercício pleno da autonomia ${ }^{6}$ governamental de cada ente federativo não transponha ou interfira no exercício das demais.

A CRFB assenta basicamente sobre dois tipos de competência: a competência administrativa e a competência legislativa. Aquela se relaciona à faculdade para operar com base no poder de polícia, e estar relacionada ao Poder Executivo, já a segunda concerne ao Poder Legislativo e tem relação à faculdade para legislar a respeito dos temas de interesse da coletividade. A primeira, não será considerada no presente estudo. Todavia, frisa-se que, quando a matéria se tratar de competência administrativa ambiental, a questão deverá ser regulamentada por lei complementar, conforme determina o parágrafo único do artigo 23 da CRFB.

No que diz respeito ao regime de competências em matéria ambiental, especificamente a de legislar sobre questões ambientais, cabe frisar a possibilidade de os entes da federação poderem legislar, criando normas de Direito Ambiental.

Nesse contexto, o que sobressai em relação à competência legislativa no Direito Ambiental é a concorrente entre União, os Estados e o Distrito Federal. Compete à União legislar acerca de normas gerais, restando aos Estados e ao Distrito Federal suplementar as normas gerais produzidas pela União.

Quando a matéria ambiental for de interesse majoritariamente local, em caráter suplementar as legislações estadual e nacional, os Municípios tem competência de legislar sobre as questões ambientais. Com isso, seria equivocado dizer que os Municípios não gozam de competência para legislar.

Relevante ainda mencionar Damásio \& Machado (2013, p. 5), o qual ressalta sobre a necessidade de o município legislar em matéria de direito ambiental "assim, tendo por base as especificidades locais, os municípios têm o desafio de equacionar seus problemas econômicos, ambientais e de segregação socioterritorial que ocorrem com o crescimento e desenvolvimento da cidade".

Com certa intervenção governamental, é possível que as noções de sustentabilidade invadam o meio urbano e o transforma numa espécie de

6 Manoel Gonçalves Ferreira Filho (1999, p. 51) afirma que a autonomia administrativa dos entes federativos pressupõe a divisão de competências entre o poder central e os poderes regionais e locais. 
ecocracia, favorecendo a criação de marcos regulatórios governamentais que auxiliem a implantação de uma consciência ambiental urbana.

Por fim, cabe destacar que, no caso de conflito de competência legislativa na matéria ambiental, deve ser adotado o Princípio da Predominância dos Interesses?.

\section{Políticas Públicas}

Essa seção da pesquisa, num primeiro momento, buscar entender os marcos institucionais que permitem a implementação das políticas públicas e a formulação de normas vigentes. Num segundo momento, tem como objetivo investigar se foram editadas normas com foco na promoção da AU a nível local.

Um estudo prévio é primordial no desenvolvimento de políticas agrícolas urbanas eficazes, a nível local, incluindo aqueles necessários para a produção de alimentos em menor escala (Kremer \& Deliberty, 2011, p. 1260).

As políticas públicas representam o conjunto das ações do governo que buscam efetivar direitos assegurados aos cidadãos e considerados prioritários num dado momento histórico.

Políticas Públicas, segundo Guareschi et al. (2004, p. 180) é "o conjunto de ações coletivas voltadas para a garantia dos direitos sociais, configurando um compromisso público que visa dar conta de uma determinada população, em diversas áreas. Expressa a transformação daquilo que é do âmbito privado em ações coletivas no espaço público.

O objetivo das políticas públicas é promover o desenvolvimento, ampliar e efetivar direitos de cidadania, de acordo com as necessidades da geração atual e futura. No caso do tema específico da pesquisa, há de se falar em políticas públicas que tenham como objeto o meio ambiente, notadamente direcionadas a sustentabilidade urbana, por meio da AU.

As políticas públicas voltadas para o incentivo e a implementação da AU são defendidas sob alegação de favorecer e promover o desenvolvimento local das periferias de grandes cidades. Para Machado \& Machado (2002, p. 9), vão além desse propósito "pelo redirecionamento dos

7 O princípio geral que norteia a repartição de competência entre as entidades componentes do Estado Federal é o da predominância do interesse. Segundo este princípio à União caberá as matérias e as questões de interesse geral, aos Estados as de interesse regional e aos Municípios as de interesse local, ao Distrito Federal tocarão as matérias de interesses regionais e locais, com algumas exceções previstas na própria C.F/1988. 
objetivos da comunidade com ações participativas em todos os processos de desenvolvimento, é possível oferecer opções de vida saudável para jovens e crianças, além de gerar empregos e melhorar a qualidade de vida das pessoas idosas ou desempregadas".

As políticas urbanas devem ser idealizadas e realizadas de forma descentralizada e agregadas às políticas sociais e de desenvolvimento urbano, com cooperação entre a União, os Estados e os municípios.

Nesse contexto, a crescente prática da AU no mundo contemporâneo torna necessário políticas públicas de âmbito nacional, regional e local, para sua implementação, fortalecimento e organização.

A inserção da Agricultura Urbana nas Políticas Públicas

O panorama de distintas reivindicações por políticas públicas para a cidade, sobretudo para AU, com objetivo em tornar as cidades mais sustentáveis exigiu a deflagração de ações que pudessem levar ao desenvolvimento local, levando em consideração as dimensões ambientais, culturais, econômicas, regionais e sociais.

Para Moreira (2008, p. 251), cabe ao Estado:

[...] desempenhar o papel de defesa e promoção da Agricultura Urbana, por meio da criação de mecanismos e ações de governo, caso contrário, certamente a Agricultura Urbana sofrerá restrições e constrangimentos para avançar e se tornar atividade possível e viável para o necessário enfrentamento da pobreza e do desemprego urbano. (Moreira, 2008, p. 251).

Sob a perspectiva de sustentabilidade urbana, o conceito de planejamento e política, surgiu pela primeira vez no Capítulo II - da Política Urbana $^{8}$ - Título VII, da CRFB e recepciona o Estatuto da Cidade, regulamentado na Lei ${ }^{\circ} 10.257 / 2001$, que contempla no Art. $2^{\circ}$, entre alguns objetivos da política urbana, a importância das cidades sustentáveis e planejadas, por intermédio dos incisos I, IV, VII e VIII:

Art. $2^{\circ}$ A política urbana tem por objetivo ordenar o pleno desenvolvimento das funções sociais da cidade e da propriedade urbana, mediante as seguintes diretrizes gerais: [...].

8 Art. 182 da CRFB de 1988: “A política de desenvolvimento urbano, executada pelo Poder Público municipal, conforme diretrizes gerais fixadas em lei, tem por objetivo ordenar o pleno desenvolvimento das funções sociais da cidade e garantir o bem-estar de seus habitantes." 
I - garantia do direito a cidades sustentáveis, entendido como o direito à terra urbana, à moradia, ao saneamento ambiental, à infraestrutura urbana, ao transporte e aos serviços públicos, ao trabalho e ao lazer, para as presentes e futuras gerações;

IV - planejamento do desenvolvimento das cidades, da distribuição espacial da população e das atividades econômicas do Município e do território sob sua área de influência, de modo a evitar e corrigir as distorções do crescimento urbano e seus efeitos negativos sobre o meio ambiente;

VII - integração e complementaridade entre as atividades urbanas e rurais, tendo em vista o desenvolvimento socioeconômico do município e do território sob sua área de influência; [...]

VIII - adoção de padrões de produção e consumo de bens e serviços e de expansão urbana, compatíveis com os limites da sustentabilidade ambiental, social e econômica do município e do território sob sua área de influência; [...].

Como visto, a sustentabilidade urbana tem tratamento constitucional, determinando que as diretrizes gerais sejam fixados na Lei Federal $\mathrm{n}^{\mathrm{o}}$ 10.257, de 10 de julho de 2001 (Estatuto da Cidade), sendo que a política de desenvolvimento urbano será executada pelo Poder Público municipal, por meio do Plano Diretor, tendo um papel medular de organização urbanística da cidade (Figura 6).

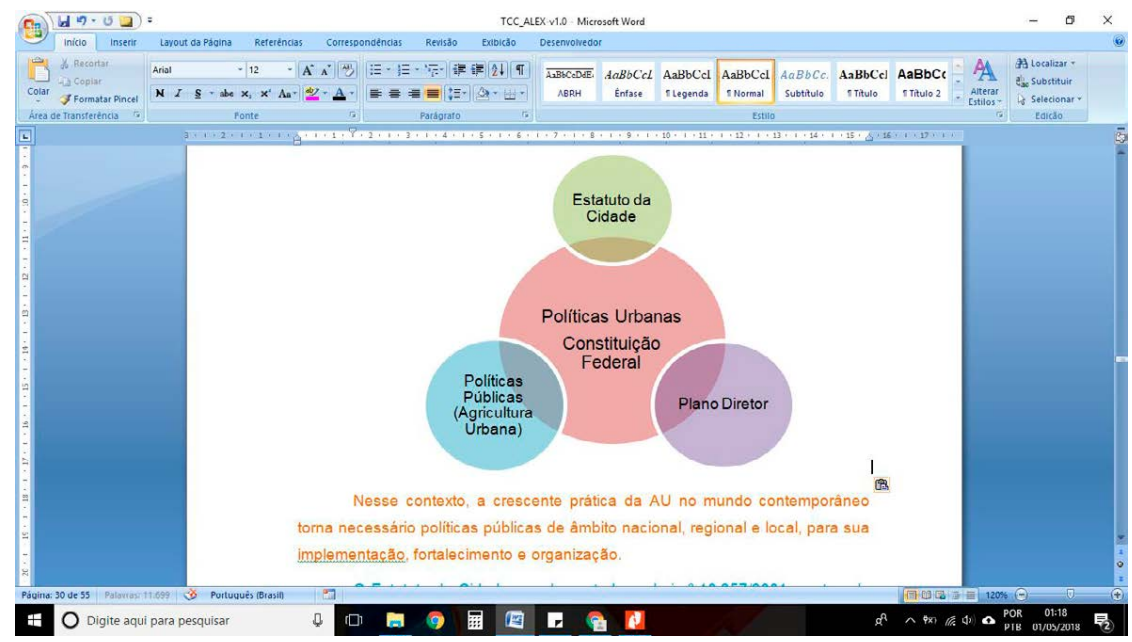

Figura 6. Tratamento constitucional de políticas que versam sobre sustentabilidade urbana.

Fonte: Elaboração própria (2018). 
Contudo, as ações na esfera do Governo Federal Brasileiro têm seu início a partir de 2003, em consonância com um conjunto de políticas de Segurança Alimentar e Nutricional (Coutinho, 2011, p. 50).

Recentemente, o Ministério do Desenvolvimento Sustentável, por meio da Portaria $n^{\circ}$ 467, de 07 de fevereiro de 2018, instituiu o Programa Nacional de AU e Periurbana, que conta com iniciativas como: potencializar as ações de segurança alimentar e nutricional; contribuir para a inclusão social de moradores urbanos, em especial das mulheres; promover a utilização de tecnologias agroecológicas; promover a educação ambiental; estimular o reaproveitamento e reciclagem de resíduos orgânicos; estimular o convívio social e as atividades culturais relacionados com a produção agrícola; assegurar a capacitação técnica e de gestão aos agricultores urbanos; estimular hábitos saudáveis de alimentação; estimular hábitos sustentáveis; e, implantar a produção com fins pedagógicos em instituições de ensino, instituições de saúde, instituições religiosas, estabelecimentos penais e de internação socioeducativa dentre outras instituições e associações (Silva, 2018).

Essa mesma portaria, aduz como metas, em seu artigo $3^{\circ}$, o seguinte:

I - formalizar parcerias na perspectiva de promover a agricultura urbana, na forma de produção agrícola sustentável, comunitária e/ou doméstica, por meio da introdução de tecnologias de produção sustentáveis como catalizador da segurança alimentar, geração de renda e inclusão social;

II - fomentar o desenvolvimento de ações voltadas para a gestão e o aperfeiçoamento das ações de agricultura urbana e periurbana;

III - promover a conscientização de possíveis financiadores para a agricultura urbana e periurbana;

IV - sensibilizar as esferas estaduais e municipais para desenvolver políticas regionais e municipais de agricultura urbana e periurbana, principalmente nas escolas e associações comunitárias.

Chama a atenção o Projeto de Lei n ${ }^{\circ}$ 906/2015, do Poder Legislativo Federal, que institui a Política Nacional de Agricultura Urbana. A proposta permite que o governo federal possa apoiar os municípios na definição de áreas aptas ao desenvolvimento de AU comunitária e individual, bem como auxiliar as prefeituras na prestação de assistência técnica e viabilizar a aquisição de produtos para os programas governamentais de aquisição de alimentos e a alimentação escolar. O projeto descreve como objetivos, 
entre outros: ampliar a segurança alimentar e nutricional das populações urbanas vulneráveis; propiciar a ocupação de espaços urbanos ociosos; gerar alternativa de renda e de atividade ocupacional à população urbana; e articular a produção de alimentos nas cidades. Na situação atual, o referido projeto foi encaminhado ao Senado Federal, onde será apreciado.

O mencionado projeto de lei define ainda, em seu artigo $3^{\circ}$, que a AU deverá estar prevista nos institutos jurídicos, tributários e financeiros contidos no planejamento municipal, especialmente nos planos diretores ou nas diretrizes gerais de uso e ocupação do solo urbano, com o objetivo de abranger aspectos de interesse local e garantir as funções sociais da propriedade e da cidade.

Em contrapartida, já a nível local, a AU começou a ser incluída nas agendas políticas brasileiras, a partir da década de 1980, a começar de iniciativas de algumas Prefeituras municipais (Santandreu \& Lovo, 2007, p. 59).

Aduz Santandreu \& Lovo (2007, p. 51) que o Brasil carece de políticas públicas, quando se fala em $\mathrm{AU}$.

Em termos gerais, não existe no Brasil uma política de AUP. Na maior parte dos casos existem as chamadas "hortas escolares" "hortas em quintais" ou "hortas comunitárias" que desenvolvem atividades de forma isoladas. Mais recentemente, com a implementação do Programa Fome Zero, muitas hortas vincularam-se às políticas de segurança alimentar e nutricional e muitos dos agricultores urbanos passaram a ser grupos alvos de programas como a Bolsa Família. Mas, a agricultura praticada por eles nem sempre são efetivamente apoiadas. O Brasil conta com políticas de combate à pobreza e fome, mas estas políticas não têm potencializado a agricultura urbana como solução ou "porta de saída" para a condição de pobreza e fome. Santandreu \& Lovo (2007, p. 51).

Neste diapasão, para alcançar o objetivo principal do presente trabalho, os estudos se centraram em identificar a legislação específica em Agricultura Urbana a nivel local.

Frisa-se que o artigo 151, da Lei Orgânica do município de João Pessoa, de 1990, alude que, para o planejamento municipal deve haver a integração entre políticas urbanas, sociais e econômicas, com a finalidade de atingir o pleno desenvolvimento das funções sociais da cidade e o bem-estar dos seus habitantes. 
O principal instrumento de organização da cidade é o Plano Diretor", sob a perspectiva da sustentabilidade urbana. Convém destacar que a presente norma, da cidade de João Pessoa, foi instituída no ano de 1992 e teve sua última revisão no ano de 2009. Tal revisão tem disposição no Art. 40, $\S 3^{\circ}$ do Estatuto da Cidade, onde disciplina que a lei que institui o plano deve ser revista, pelos menos, a cada dez anos. Portanto, o Plano Diretor é dinâmico, assim como a humanidade.

Após leitura detalhada do Plano Diretor, identifica-se que não há pontos essenciais no tocante a AU, contudo, observam-se pontos no que diz respeito à sustentabilidade, como: uso e ocupação do solo e mobilidade urbana.

Todavia, o artigo $4^{\circ}$, inciso XIII, da lei em comento, considera como exigência e condição fundamental para ordenamento e gestão do espaço urbano o interesse em matérias referentes ao meio ambiente e suprimento alimentar, conforme se ler:

XIII - o planejamento e a gestão municipais estabelecerão mecanismos estáveis de articulação entre o Município de João Pessoa, os Governos do Estado da Paraíba e da União e, os demais Municípios com interesses comuns, notadamente aqueles concernentes ao transporte coletivo, sistema viário, meio ambiente, suprimento alimentar, abastecimento de água, tratamento de esgotos, disposição final do lixo, energia, localização industrial, incentivos ao investimento privado e parcelamento do uso do solo.

Ainda nessa temática, o referido Plano Diretor trata como objetivos meios, entre outros, da política urbana, no artigo $3^{\circ}$, XI e XII, a garantia à sustentabilidade urbana, bem como o planejamento do desenvolvimento da cidade.

XI - garantia à cidade sustentável, à terra urbana, à moradia, ao saneamento ambiental, à infraestrutura urbana, ao transporte e aos serviços públicos, ao trabalho e ao lazer, para a população;

XII - planejamento do desenvolvimento da cidade, da distribuição espacial da população, do transporte e das atividades econômicas do Município e do território sob sua área de influência, de modo a evitar e corrigir as distorções do crescimento urbano e seus efeitos negativos sobre o meio ambiente.

9 O Plano Diretor da cidade de João Pessoa foi instituído pela Lei Complementar $\mathrm{n}^{\circ} 3$, de 30 de dezembro de 1992. Atualizada e consolidada até a Lei-Complementar no.4, de 30 de abril de 1993. Sendo consolidado por meio do Decreto n. ${ }^{\circ}$ 6.499, de 20 de março de 2009. 
Situação distinta foi identificada no Plano Diretor Estratégico do município de São Paulo, onde, por exemplo, a AU faz parte do plano ${ }^{10}$ (Seção X, Capítulo I), além disso, existe uma legislação específica de AUP recentemente aprovada, que inclui a Lei $\mathrm{n}^{0}$ 13.727, de 12 de Janeiro de 2004, que cria seu Programa de Agricultura Urbana e Periurbana (PROAURP) e define suas diretrizes.

Merece menção a Lei no 7.469, de 14 de dezembro de 1993, que autoriza $^{11}$ a Prefeitura Municipal de João Pessoa a celebrar comodatos ${ }^{12}$, com os proprietários de terreno que queiram disponibilizar espaços visando à implantação de hortas comunitárias. Ainda na mesma lei ${ }^{13}$, a norma prevê um desconto de 50\% no Imposto Predial Territorial Urbano (IPTU) para os proprietários dos terrenos.

O governo municipal também instituiu a Lei $\mathrm{n}^{0} 8.002$, de 30 de dezembro de 1995, que cria o Conselho de Alimentação Escolar, tendo como competência (artigo $4^{\circ}, \mathrm{X}$ ), desenvolver programas que estimulem a AU, com a instalação e manutenção de hortas, nas escolas municipais, com objetivo de enriquecimento da alimentação escolar.

Cabe destacar a pesquisa realizada por Silva (2018), onde estudou a AU praticada na cidade de João Pessoa, particularmente as hortas urbanas, como resultado identificou 65 iniciativas de hortas implantadas no meio urbano, classificando-as como: horta comunitária, escolar, particular ou terapêutica, localizadas tanto em espaço público ou privado.

No contexto das hortas urbanas foi instituído o Projeto Criar Peixes do município, Lei $\mathrm{n}^{\circ} 8.134$, de 03 de dezembro de 1996, a ser implantado nas margens do Rio Jaguaribe, em conjunto com a implantação de hortas comunitárias, nesse mesmo local.

10 A Lei $n^{\circ} 13.430$, de 13 de setembro de 2002, dispõe sobre o Plano Diretor Estratégico e o Sistema de Planejamento e Gestão do Desenvolvimento Urbano do Município de São Paulo.

11 Art. 1 da Lei nº 7.469, de 14 de dezembro de 1993: "fica a Prefeitura Municipal, de João Pessoa autorizado a celebrar contatos de comodato com proprietários de terrenos neste Município de João Pessoa, objetivando a utilização desses espaços a implantação de hortas comunitárias”.

12 Comodato é um empréstimo de algo que não pode ser substituído por outro da mesma espécie e qualidade, nesse caso, um terreno, tem previsão legal nos artigos 579 a 585 do Código Civil Brasileiro (Lei n. ${ }^{\circ} 10.406$ de 10 de janeiro de 2002).

13 Art. 1 da Lei n 7.469, de 14 de dezembro de 1993: “em contrapartida, como compensação aos proprietários que desejam beneficiar-se dos comodatos, a Prefeitura Municipal fica autorizada a abater o percentual de $50 \%$ (cinquenta por cento) sobre o pagamento do IPTU devido pelo imóvel objeto de comodato que venha a ser calculado no ano seguinte ao da realização do comodato. 
Nesse sentido tem-se a Lei ${ }^{\circ} 10.420$ de 30 de dezembro de 2004, que cria o Programa Municipal de Agricultura Urbana em João Pessoa, destaca que as áreas urbanas ociosas poderão ser ocupadas com a finalidade de produção de alimentos, como o cultivo de hortaliças, plantas medicinais, produção de mudas, leguminosas, frutas e outros alimentos. Tal programa destina-se a complementação alimentar; otimizar o aproveitamento dos espaços urbanos; geração e complementação de renda; melhoria da segurança alimentar e da saúde da população; melhorar o meio ambiente urbano mediante o zelo dos espaços ociosos; e, desenvolver hortas comunitárias. Cabendo ressaltar que, o uso desses espaços deverá ser solicitar por escrito ao Poder Executivo.

Nessa mesma Lei, o artigo $8^{\circ}$, menciona a faculdade de particulares, que possuem terrenos ociosos, serem integrados ao Programa Municipal de Agricultura Urbana mediante o consentimento expresso. Essa participação deve ser na forma de contrato de comodato entre o proprietário e a entidade que administrará o cultivo no respectivo terreno. O que já era previsto na Lei ${ }^{\circ} 7.469$, de 14 de dezembro de 1993, como visto anteriormente.

Numa mesma linha temática também foi criado o "Programa João Pessoa Cidade Verde", instituído pela Lei $n^{0} 11.838$, de 22 de dezembro de 2009, com objetivo de melhoria da qualidade de vida dos cidadãos e do ecossistema da cidade, visando o desenvolvimento de uma consciência ecológica urbana e proteção ao meio ambiente, incentivando o cultivo e plantio de árvores frutíferas e hortas comunitárias em terrenos e áreas desocupadas e lotes vazios da cidade.

Nessa perspectiva, foi instituída a Política Municipal de Apoio a Agricultura Urbana, Lei $\mathrm{n}^{\mathrm{o}}$ 12.515, de 21 de fevereiro de 2013, voltada para a segurança alimentar e nutricional sustentável da população, em bases sustentáveis. Para facilitar a operacionalização do programa, em seu parágrafo único, artigo $1^{\circ}$, a "Agricultura Urbana" foi definida como:

[...] o conjunto de atividades de cultivo de hortaliças, de plantas medicinais, de espécies frutíferas, de flores, de manejo florestal, bem como a criação de animais, a piscicultura e a produção artesanal de alimentos e bebidas para o consumo humano, a troca, a doação, a comercialização e prestação de serviços. 
Em João Pessoa, esse é o primeiro instituto normativo a fazer menção expressa ao termo "Agricultura Urbana".

De acordo com essa lei, as ações de apoio à AU dar-se-ão de forma integrada entre si, e com as ações de segurança alimentar e nutricional sustentável, de habitação, de assistência social, de saúde, de educação, de geração de emprego e renda, de formação profissional e de proteção ambiental, organizadas em redes, de forma a promover o diálogo entre os diversos setores governamentais e da sociedade civil.

Nesse diapasão, em contribuição ao tema políticas públicas voltadas para o incentivo e implementação da AU, Machado \& Machado (2002, p. 11), ressaltam que é possível favorecer e promover o desenvolvimento local das periferias de grandes cidades.

Ainda no que diz respeito a normas é interessante observar à preocupação do município com políticas públicas que visam o desenvolvimento sustentável da cidade, cabendo destacar:

A Lei $n^{0} 13.437$, de 04 de julho de 2017, que dispõe de Diretrizes para Elaboração da Lei Orçamentária para o exercício do corrente ano, 2018, tem como prioridade e metas para a Administração Municipal a instigação ao desenvolvimento sustentável e o planejamento urbano com bases sustentáveis, conforme descrito a seguir:

Art. $3^{\circ}$ As prioridades e metas da Administração Municipal para o exercício financeiro de 2018 serão fixadas considerando os seguintes princípios orientadores:

$\mathrm{X}$ - indução ao desenvolvimento sustentável da produção local através do estímulo ao empreendedorismo, ao associativismo, ao cooperativismo e aos programas de geração de ocupação e renda;

XV - planejamento urbano voltado para a construção participativa de um projeto para a cidade, em bases sustentáveis, considerando o conjunto urbano, com qualidade de vida para os cidadãos e resgate da identidade municipal.

Já o Decreto $\mathrm{n}^{\circ} 8.731$, de 18 de maio de 2016, regulamenta a realização de cooperação com a iniciativa privada e a sociedade civil organizada para a manutenção de espaços públicos no município de João Pessoa. Para tanto, o titular do Poder Executivo Municipal, atendido o interesse público, poderá celebrar Termo de Cooperação com entidades da iniciativa 
privada e da sociedade civil organizada, quais sejam associações de moradores, sociedades, amigos de bairros, centros comunitários, clubes de serviços, bem como terceiros interessados. Essa cooperação poderá ser de forma individual ou consorciada, a fim de promover melhorias urbanas mediante mútua colaboração nos serviços inerentes à implantação, reforma, manutenção e/ou conservação de parques, praças, áreas verdes, mobiliário urbano e demais espaços públicos ou livres do Município, buscando melhorias urbanas, ambientais e paisagísticas. Para fins de legislação, consideram-se melhorias urbanas, paisagísticas e ambientais os projetos, obras, serviços, ações e intervenções, relativos a bens públicos municipais e a bens privados ou públicos tombados em caráter provisório ou definitivo, ou preservados, nos termos da legislação municipal pertinente, que resultem no atendimento do interesse público e na melhoria da qualidade da vida urbana.

Nesse contexto de sustentabilidade urbana, a Secretaria de Desenvolvimento Sustentável foi transformada em Secretaria do Trabalho, Produção e Renda - Lei ${ }^{\circ} 12.465$, de 25 de janeiro de 2013 - e tem por finalidade planejar e executar políticas de emprego e renda e de apoio à formação do trabalhador, de economia solidária e de fomento à produção agrícola e ao empreendedorismo. Além disso, compete a essa Secretaria participar de atividades que estimulem o desenvolvimento sustentável, o enfrentamento da pobreza e o exercício da cidadania, como políticas de promoção do trabalho.

Por fim, identificou-se a Lei $n^{\circ} 12.188$, de 15 de setembro de 2011, que dispõe a Política Municipal de Segurança Alimentar e Nutricional no âmbito de João Pessoa, com o propósito primordial de garantir o exercício do direito humano à alimentação adequada, de forma sustentável.

Para melhor compreensão do marco legislativo e visualização da legislação relacionada à $\mathrm{AU}$ em João Pessoa, foi confeccionado uma linha do tempo de construção dessas políticas públicas (Figura 7). 
Alex Dias da Silva

A construção de políticas públicas para a sustentabilidade urbana

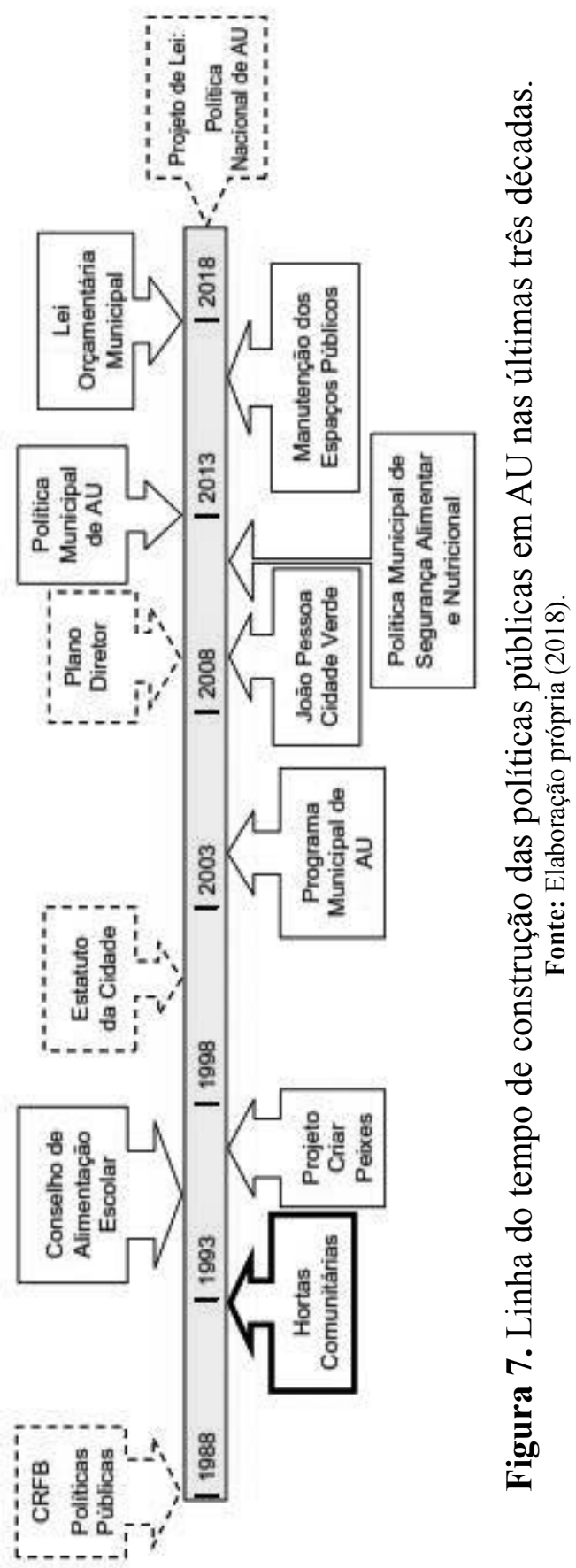


Os resultados relativos à identificação de políticas públicas em AU, em João Pessoa, foram positivos e revelou o papel do poder público na promoção da AU. Apresenta como marcos legal e institucional, o ano de 1993 com a instituição da Lei n$^{\circ} 7.479$, de 14 de dezembro, que visa à implantação de hortas comunitárias em espaços de terrenos de particulares.

Entre a diversidade de normas, além do marco institucional supramencionado, em especial no que diz respeito a implantação de hortas, tem-se: a criação do Conselho de Alimentação Escolar (1995), o Projeto Criar Peixes (1996), o Programa Municipal de AU (2004), o Programa João Pessoa Cidade Verde (2009), a Política Municipal de Apoio a Agricultura Urbana (2013). O processo de formulação e implementação das políticas de AU ocorreu de maneira diferente e mais acelerada, quando comparada às políticas de $\mathrm{AU}$ a nível nacional.

Por fim, ressalta-se a existência de legislação correlata, que de algum modo, tem conexão com a AU, a saber: Política Municipal de Segurança Alimentar e Nutricional (2011), a criação da Secretaria do Trabalho, Produção e Renda (2013), a Manutenção de Espaços Públicos de Forma Sustentável (2016) e Diretrizes para Elaboração da Lei Orçamentária (2017).

Nesta perspectiva, tendo em vista a crescente prática da AU no cenário nacional e local, vislumbra-se a construção coletiva das bases de políticas públicas para seu fortalecimento e organização (Silva, 2018).

\section{Considerações Finais}

São evidentes as políticas de desenvolvimento urbano no município de João Pessoa, os marcos legais e diretrizes da AU surgem na legislação municipal dentro do escopo das Políticas Públicas, com vistas a assegurar o direito segurança alimentar, bem como a preservação do meio ambiente. Todavia, a concretização dessas diretrizes depende da prestação positiva do Poder Executivo e do controle e fiscalização da sociedade para que sejam aplicadas.

De forma geral, no município de João Pessoa se identificou legislação específica que promove o desenvolvimento de ações no sentido de incentivar as diversas formas de cultivo do solo para produção de alimentos na zona urbana. Inclui diversos subprogramas de AU como: hortas privadas; hortas comunitárias; hortas escolares e hortas institucionais. Essa legislação prevê uma gestão integrada e cooperação entre os entes federados na consecução das políticas. 
Pode-se inferir que a promoção da AU contribui para tornar as cidades mais sustentáveis e socialmente mais justas, podem dá a oportunidade de acesso à terra para aqueles que estão sendo excluídos pelo processo de modernização capitalista. A harmonização entre essas políticas e a segurança alimentar amplifica o espaço dos agricultores familiares, ampliando assim a oferta de alimentos e reduzindo a pobreza e desigualdade.

Diante desses fatos, não há como negar que nos últimos trinta anos houve uma verdadeira revolução quanto às políticas públicas no ambiente urbano nacional, em especial a AU em João Pessoa. No entanto, há de se considerar os desafios para sua implantação, fiscalização e sustentação.

Outra situação que merece destaque é que a AU não foi incluída no atual Plano Diretor do município de João Pessoa, restando esse desafio para ações futuras, no tocante a revisão do referido Plano.

Por fim, deve-se considerar o diálogo das legislações já em vigência nas esferas Federal, Estadual e Municipal, para alcançar uma eficácia e efetividade das políticas públicas voltadas para o desenvolvimento da AU sustentável. Com certa intervenção governamental e empresarial, é possível que as noções de sustentabilidade invadam o meio urbano e o transforma numa espécie de ecocracia, favorecendo a criação de marcos regulatórios governamentais que auxiliem a implantação de uma consciência ambiental urbana.

A AU é um campo de inovação promissor, e deve ser desenvolvida e consolidada, juntamente, com os programas de políticas urbanas, como uma estratégia de melhoria da qualidade nutricional e geração de renda das famílias urbanas.

\section{Referências}

Barbieri, J. C., \& Cajazeira, J. E. R. (2009). Responsabilidade social empresarial e empresa sustentável: da teoria à prática. São Paulo: Atlas. Brasil. (1981). Lei $n^{\circ}$ 6.938, de 31 de agosto de 1981. Dispõe sobre a Política Nacional do Meio ambiente, seus fins e mecanismo de formulação e aplicação, e dá outras providências. Recuperado de http:// www.planalto.gov.br/ccivil_03/Leis/L6938.htm.

Brasil. (1985). Lei $n^{\circ} 7.347$, de $2 \overline{4}$ de julho de 1985. Disciplina a ação civil pública de responsabilidade por danos causados ao meio-ambiente, ao consumidor, a bens e direitos de valor artístico, estético, histórico, 
turístico e paisagístico (VETADO) e dá outras providências. Recuperado de http://www.planalto.gov.br/ccivil_03/Leis/L7347orig.htm.

Brasil. (1988). Lei $n^{\circ}$ 9.605, de 12 de fevereiro de 1988. Dispõe sobre as sanções penais e administrativas derivadas de condutas e atividades lesivas ao meio ambiente, e dá outras providências. Recuperado de http://www.planalto.gov.br/ccivil_03/Leis/L9605.htm.

Brasil. (1988). Constituição Federal da República (CF/88). Recuperado de http://www.planalto.gov.br/ccivil_03/Constituicao/Constituicao.htm.

Brasil. (2001). Lei $n^{o} 10.257$, de 10 de julho de 2001. Regulamenta os arts. 182 e 183 da Constituição Federal, estabelece diretrizes gerais da política urbana e dá outras providências. Recuperado de http://www. planalto.gov.br/ccivil_03/Leis/LEIS_2001/L10257.htm.

Brasil. (2002). Lei $n .^{\circ} 10.406$, de 10 de janeiro de 2002. Institui o Código Civil. Recuperado de http://www.planalto.gov.br/CCivil_03/ Leis/2002/L10406.htm.

Brasil. (2015). Projeto de Lei $n^{\circ}$ 906, de 25 de março de 2015, do Poder Legislativo Federal. Institui a Política Nacional de Agricultura Urbana e dá outras providências. Recuperado de http://www.camara. gov.br/proposicoesWeb/ficha?i1150824.

Câmara Municipal de São Paulo. (2002). Lei $n^{\circ} 13.430$, de 13 de setembro de 2002. Dispõe sobre o Plano Diretor Estratégico e o Sistema de Planejamento e Gestão do Desenvolvimento Urbano do Município de São Paulo. Recuperado de http://www.prefeitura.sp.gov.br.

Câmara Municipal de São Paulo. (2004). Lei $n^{o}$ 13.727, de 12 de janeiro de 2004. Cria o Programa de Agricultura Urbana e Periurbana (PROAURP) no município de São Paulo e define suas diretrizes. Recuperadodehttp://www3.prefeitura.sp.gov.br/cadlem/secretarias/negocios juridicos/cadlem/integra.asp?alt=13012004L\%20137270000.

Casa de Napoleão Laureano. (1990). Lei Orgânica para o Município de João Pessoa, de 1990. Recuperado de http://www.joaopessoa. pb.gov.br/portal/wp-content/uploads/2012/04/Lei_Organica_de_ Joao_Pessoa.pdf.

Casa de napoleão Laureano. (1992). Lei Complementar $n^{\circ} 3$, de 30 de dezembro de 1992. Institui o Plano Diretor da Cidade de João Pessoa. Recuperado de http:/www.joaopessoa.pb.gov.br/secretarias/seplan/ plano-diretor/. 
Casa de Napoleão Laureano. (1993). Lei $n^{\circ} 7.469$, de 14 de dezembro de 1993. Autoriza a prefeitura municipal de João Pessoa a celebrar comodatos visando a implantação de hortas comunitárias, e dá outras providências. Recuperado de https://leismunicipais.com.br/a/pb/j/ joao-pessoa/lei-ordinaria/1993/747/7469.

Casa de Napoleão Laureano. (1995). Lei $n^{\circ} 8.002$, de 30 de dezembro de 1995. Institui, na administração municipal o Conselho de Alimentação Escolar, a que se refere a Lei Federal no 8.913, de 12 de julho de 1994. Recuperado de https://leismunicipais.com.br/a/pb/j/ joao-pessoa/lei-ordinaria/1995/801/8002.

Casa de Napoleão Laureano.(1996).Lein ${ }^{\circ}$ 8.134, de 03 de dezembrode 1996. Autoriza a criação do Projeto Criar Peixes. Recuperado de https://leismunicipais.com.br/a/pb/j/joao-pessoa/lei-ordinaria/1996/814/8134/ lei-ordinaria-n-8134-1996-autoriza-a-criacao-do-projeto-riar-peixes.

Casa de Napoleão Laureano. (2004). Lei $n^{\circ} 10.420$, de 30 de dezembro de 2004. Institui o Programa Municipal de Agricultura Urbana em João Pessoa e adota outras providências. Recuperado de https://leismunicipais.com.br/a/pb/j/joao-pessoa/lei-ordinaria/10420.

Casa de Napoleão Laureano. (2009). Lei $n^{\circ} 11.838$, de 22 de dezembro de 2009. Autoriza o Poder Executivo a criar e implantar o "Programa João Pessoa Cidade Verde" e dá outras providências. Recuperado de https://leismunicipais.com.br/a/pb/j/joao-pessoa/ lei-ordinaria/2009/1184/11838.

Casa de Napoleão Laureano. (2011). Lei $n^{\circ} 12.188$, de 15 de setembro de 2011. Dispõe sobre a Política Municipal de Segurança Alimentar e Nutricional no âmbito do município de João Pessoa e dá outras providências. Recuperado de https://leismunicipais.com.br/a/pb/j/ joao-pessoa/lei-ordinaria/2011/1219/12188-dispoe-sobre-a-politicamunicipal-de-seguranca-alimen.

Casa de Napoleão Laureano. (2013). Lei $n^{\circ} 12.465$, de 25 de janeiro de 2013. Transforma a Secretaria de Desenvolvimento Sustentável da Produção em Secretaria do Trabalho, Produção e Renda - Secretaria do Trabalho; dispõe sobre sua estrutura, seus cargos em comissão e dá outras providências. Recuperado de https://leismunicipais.com. br/pb/j/joao-pessoa/lei-ordinaria/2013/1246/12465/lei-ordinaria-n12465-2013-transforma-a-secretaria-de-desenvolvimento-sustenta- 
vel-a-producao-em-secretaria-do-trabalho-producao-e-renda-secretaria-do-trabalhoispoe-sobre-sua-estrutura-seus-cargos-em-comissao-eda-outras-providencias-2013-01-25.html.

Casa de Napoleão Laureano. (2013). Lei $n^{o} 12.515$, de 21 de fevereiro de 2013. Institui a "Política Municipal de Apoio a Agricultura Urbana", e dá outras providências. Recuperado de https://leismunicipais.com. br/a/pb/j/joao-pessoa/lei-ordinaria/2013/1252/12515/lei-ordinarian-12515-2013-institui-a-politica-municipal-de-apoio-a-agriculturaurbana-e-da-outras-providencias.

Casa de Napoleão Laureano. (2016). Decreto $n^{\circ} 8.731$, de 18 de maio de 2016. Regulamenta a realização de cooperação com a iniciativa privada e a sociedade civil organizada para a manutenção de espaços públicos no município de João Pessoa. Recuperado de https:// leismunicipais.com.br/a/pb/j/joao-pessoa/decreto/2016/874/8731/ decreto-n-8731-2016-regulamenta-a-realizacao-de-cooperacaocom-a-iniciativa-privada.

Casa de Napoleão Laureano. (2018). Lei $n^{\circ} 13.437$, de 04 de julho de 2017. Dispõe sobre as Diretrizes para Elaboração da Lei Orçamentária para o exercício de 2018, e dá outras providências. Recuperado de http://www.joaopessoa.pb.gov.br/portal/wp-content/ uploads/2017/07/2017_1588-Especial-LDO_2018-01.pdf.

Coutinho, M. N. (2010). Agricultura Urbana: práticas populares e sua inserção em políticas públicas. Dissertação de Mestrado - Geografia/UFMG. Recuperado de http://www.bibliotecadigital.ufmg.br/ dspace/handle/1843/MPBB-87YHD5.

Damásio, C., \& Machado, G. (2013). Plano Diretor participativo: leitura da realidade. Prefeitura Municipal de Feliz. Feliz. Recuperado de http://www.feliz.rs.gov.br/web/imgs/arquivos/leitura-da-realidade244-mb.pdf.

Guareschi, N., Comunello, L. N., Nardini, M., \& Hoenisch, J. C. (2004). Problematizando as práticas psicológicas no modo de entender a violência. In: Violência, gênero e Políticas Públicas. Orgs: Strey, M. N.; Azambuja, M. P. R.; Jaeger, F. P. Ed: EDIPUCRS, Porto Alegre. Recuperado de http://pt.wikipedia.org/wiki/ Pol\%C3\%ADtica_p\%C3\%BAblica. 
Kremer, P., \& Deliberty, T. L. (2011). Local food practices and growing potential: Mapping the case of Philadelphia. Applied Geography. Vol. 31, pp. 1252-1261. Recuperado de https://doi.org/10.1016/j. apgeog.2011.01.007.

Machado, A. T., \& Machado, C. T. T. (2002). Agricultura Urbana. Planaltina, DF: Embrapa Cerrados. (Documentos/Embrapa Cerrados). Recuperado de http://bbeletronica.cpac.embrapa.br/versaomodelo/ $\mathrm{html} / 2002 /$ doc/doc_48.shtml.

Ministério do Desenvolvimento Social. (2018). Portaria $n^{\circ} 467$, de 07 de fevereiro de 2018. Institui o Programa Nacional de Agricultura Urbana e Periurbana.

Moreira, C. (2008). Trajetória contemporânea da agricultura urbana. In: HISSA, Cássio Eduarno Viana. Saberes Ambientais: desafios para o conhecimento disciplinar. Belo Horizonte: UFMG. pp. 243-257.

Mougeot, L. J. A. (2000). Urban Agriculture: Definition, Presence, Potentials AndRisks. In: Growing Cities, Growing Food, Urban Agriculture on the Policy Agenda, DSE, pp. 1-41. Recuperado de https://idlbnc-idrc.dspacedirect.org/bitstream/handle/10625/26429/117785. pdf? sequence $=12$.

Onu. (2015). Transformando Nosso Mundo: A Agenda 2030 para o Desenvolvimento Sustentável. Recuperado de https://nacoesunidas.org/ wp-content/uploads/2015/10/agenda2030-pt-br.pdf.

Pinto, R. F. (2007). Hortas Urbanas: espaços para o desenvolvimento sustentável de Braga. Dissertação de Mestrado em Engenharia Municipal, Área de especialização em Planejamento Urbanístico, Universidade do Minho, Braga, p. 54. Recuperado de http://hdl.handle. net/1822/7988.

Ruppenthal, J. E. (2014). Gestão ambiental. Santa Maria: Universidade Federal de Santa Maria, Colégio Técnico Industrial de Santa Maria; Rede e-Tec Brasil.

Santandreu, A., \& Lovo, I. (2007). Panorama da Agricultura Urbana e Periurbana no Brasil e Diretrizes Políticas para sua Promoção: identificação e caracterização de iniciativas de agricultura urbana e periurbana em regiões metropolitanas brasileiras. Belo Horizonte: IPES; REDES. 
Silva, A. D. (2018). Produção de alimentos na cidade: uma estratégia para o desenvolvimento local sustentável a partir de experiências em João Pessoa-PB. Dissertação (Mestrado em Engenharia Civil e Ambiental) - Universidade Federal da Paraíba, João Pessoa. Recuperado de https://repositorio.ufpb.br/jspui/handle/123456789/14025.

Stewart, R., Korth, M., Langer, L., Rafferty, S., Silva, N. R., \& Van Rooyen, C. (2013). What are the impacts of urban agriculture programs on food security in low and middle-income countries? Environmental Evidence, v. 2, n. 1, p. 1-10. Recuperado de https://doi. org/10.1186/2047-2382-3-21.

Tabosa, R. M. R., Afonso, F. V., Silveira, J. A. R., \& Donegan, L. (2018). (Re)pensando Espaços Livres Públicos em João Pessoa: Uma proposta para os bairros Expedicionários, Tambauzinho e Miramar. Revista Nacional de Gerenciamento de Cidades, [S.1.], v. 6, n. 38. Recuperado de http://dx.doi.org/10.17271/2318847263820181546.

Veiga, J. E (2010). Desenvolvimento sustentável: o desafio do século XXI. Rio de Janeiro: Garamond. 
